\title{
Mempelajari Reaksi Transesterifikasi Terkatalisis Kalsium Oksida
}

\author{
Nia Yuniar Kandou*,Sanusi Gugule, Anderson A. Aloanis
}

aKimia, Universitas Negeri Manado, Tondano, 95618, Indonesia

\begin{tabular}{l} 
I N F O A R T I K E L \\
\hline Diterima 6 Juli 2020 \\
Disetujui 26 Oktober 2020 \\
\\
\hline Key word: \\
Transesterification reaction, \\
virgin coconut oil, \\
calcium oxide. \\
\hline Kata kunci: \\
Reaksi Transesterifikasi, \\
virgin coconut oil, \\
kalsium oksida.
\end{tabular}

${ }^{*} e$-mail:

niayuniar.kandou98@gmail.com

\begin{abstract}
A B STR A C T
Research on the virgin coconut oil transesterification reaction catalyzed calcium oxide has been carried and determination of its characteristics include physico-chemical properties, analysis of reactions results using infrared spectrophotometer and gas chromatography-mass spectrometer (GCMS). The purpose of this research is to study the transesterification reaction catalyzed calcium oxide and find out its characteristics. VCO transesterification reaction catalyzed calcium oxide was carried out for 3 hours at a temperature $70^{\circ} \mathrm{C}$ with a catalyst of $1 \%$. The results of this reaction have as much yield; 39,89\% and the alleged characteristic change due to new ester that is, density $0,88 \mathrm{~g} / \mathrm{mL}$, kinematic viscosity 2,73 $\mathrm{mm}^{2} / \mathrm{s}$ (cSt), acid number 0,59 $\mathrm{mg} \mathrm{KOH} / \mathrm{g}$, ester number 148,43 $\mathrm{mg} \mathrm{KOH} / \mathrm{g}$ and peroxide number 4,27 mek $\mathrm{O}_{2} / \mathrm{kg}$. The results of infrared spectrophotometry analysis showed absorption bands for ester and GCMS analysis gave the peak of the compound suspected as ethyl ester with three peaks which had the most abundance in the form of ethyl laurate $58,32 \%$, ethyl myristate $16,82 \%$ and ethyl palmitate $6,92 \%$.
\end{abstract}

\section{Pendahuluan}

Kelapa adalah tumbuhan yang dapat diolah untuk dijadikan minyak dimana minyak kelapa dapat digunakan sebagai bahan baku dalam reaksi transesterifikasi karena mengandung trigliserida. Komponen trigliserida dapat dipertahankan apabila minyak berada dalam keadaan murni. Asam lemak yang terdapat dalam virgin coconut oil berupa asam Kaprilat, asam kaprat, asam laurat, asam miristat, asam palmitat, asam stearat, asam oleat dan asam linoleat [1]. Rendemen virgin coconut oil yang bisa didapatkan mencapai 20,28\% dengan karakteristik yang memenuhi syarat untuk sampel dalam reaksi transesterifikasi [2].

Katalis heterogen dikembangkan untuk mengatasi masalah penggunaan katalis 
homogen dan enzim [3]. Salah satu katalis heterogen yang dapat digunakan adalah kalsium oksida karena tidak larut dalam ester dan memiliki aktifitas katalis yang tinggi.

\section{Bahan dan Metode}

Bahan yang digunakan dalam penelitian ini adalah virgin coconut oil, etanol p.a merck, $\mathrm{KOH}$ p.a merck, $\mathrm{HCl}$ p.a merck, fenolftalein p.a merck, kloroform p.a merck, asam asetat p.a $99,8 \%$, KI p.a 99,5\%, aquades $97 \%$, kanji p.a, $\mathrm{CaO}$ p.a $97 \%$, natrium tiosulfat p.a $97 \%$. Peralatan yang digunakan dalam penelitian ini berupa, Seperangkat alat refluks, timbangan analitik, alat-alat gelas, hot plate, pipet tetes, botol vial, viskometer, piknometer, oven, furnace, batang pengaduk, spatula, ayakan 44 mesh, kertas saring whattman no.42, corong buchner, pompa vakum, corong biasa, wadah bening, selang, plastik bening, gunting, kain bersih, mixer, kromatografi gas-spektrometer massa dan spektrofotometer inframerah.

\section{Pembuatan Virgin Coconut Oil}

Virgin coconut oil dalam penelitian ini dibuat dengan memisahkan daging kelapa dan kulit arinya kemudian digiling. Setiap $1 \mathrm{Kg}$ daging kelapa giling kemudian ditambahkan 1,5 liter air kelapa dan diperas untuk menghasilkan santan. Santan di diamkan hingga terbentuk dua lapisan kemudian ambil bagian atas dari lapisan tersebut dan mikser selam 1 jam dan dilanjutkan dengan fermentasi secara alami selama 10 jam [1]. Minyak yang diperoleh kemudian disaring dan ditentukan massa jenis, viskositas, bilangan asam, bilangan peroksida dan bilangan ester [4].

\section{Preparasi Kalsium Oksida}

Kalsium oksida 97\% di haluskan dan diayak lalu di panaskan pada temperatur $800^{\circ} \mathrm{C}$ selama 2 jam. Hasil pemanasan tersebut kemudian didinginkan dalam desikator lalu ditimbang [5].

\section{Reaksi Transesterifikasi}

Reaksi transesterifikasi dilakukan dengan menambahkan $1 \%$ kalsium oksida ke dalam etanol $98 \%$ dengan perbandingan mol minyak:alkohol yang digunakan dalam penelitian ini sebesar 1:12, waktu reaksi selama
3 jam pada temperatur $70^{\circ} \mathrm{C}$. Setelah itu, dilakukan pemisahan katalis dengan cara disaring dan dilanjutkan dengan pencucian menggunakan akuades. Selanjutnya hasil pencucian dikeringkan pada temperatur $105^{\circ} \mathrm{C}$ [6]. Hasil ini kemudian dianalisis menggunakan IR dan KGSM

\section{Hasil dan Pembahasan}

Pembuatan virgin coconut oil

Zat pengemulsi dalam santan diganggu ikatannya dengan cara mengaduk santan tersebut dan dilanjutkan dengan fermentasi sehingga minyak dapat keluar. Waktu fermentasi dibatasi selama 10 jam untuk mencegah bilangan asam yang terlalu tinggi selain itu, pemanasan juga tidak dilakukan agar bilangan peroksida tidak terlalu tinggi (tabel 1).

Tabel 1. Karakteristik virgin coconut oil

\begin{tabular}{cc}
\hline Parameter & $\begin{array}{c}\text { Karakteristik Virgin } \\
\text { Coconut Oil }\end{array}$ \\
\hline Rendemen & $19,55 \%$ \\
Massa Jenis Pada & $0,92 \mathrm{~g} / \mathrm{mL}$ \\
$40^{\circ} \mathrm{C}$ & $0,43 \%$ \\
Kadar air & $9,61 \mathrm{~mm}^{2} / \mathrm{s}(\mathrm{cSt})$ \\
Viskositas Kinematik & Bening \\
Warna & Khas minyak kelapa \\
Bau & $0,49 \mathrm{mg} \mathrm{KOH} / \mathrm{g}$ \\
Bilangan Asam & $0,40 \mathrm{mekO} / \mathrm{kg}$ \\
Bilangan Peroksida & $146,23 \mathrm{mg} \mathrm{KOH} / \mathrm{g}$ \\
Bilangan Ester
\end{tabular}

Fermentasi dilakukan secara alami untuk menghindari bahan tambahan yang mungkin dapat mempengaruhi kualitas VCO selain itu, teknik ini juga lebih sederhana dibandingkan teknik pembuatan VCO lainnya. Dari karakteristik VCO yang disajikan pada tabel 1, maka diketahui bahwa VCO yang dihasilkan dapat digunakan sebagai bahan baku dalam reaksi transesterifikasi karena syarat untuk bahan baku dengan katalis basa dalam reaksi transesterifikasi adalah kadar asam lemak bebas maksimal 3\% dan kadar air harus dibawah $1 \%$ [7].

\section{Preparasi Kalsium Oksida}

Pada saat proses penghalusan tersebut kalsium oksida mungkin telah mengabsorbi senyawa yang ada di udara. Kalsium oksida 
mudah mengabsorbsi uap air dan karbondioksida dari udara bahkan dalam rentan waktu 5 menit [8]. Akibat dari absorbsi tersebut adalah terbentuknya kalsium hidroksida dan kalsium karbonat dimana kedua senyawa tersebut dapat mengurangi aktifitas kalsium oksida yang akan bertindak sebagai katalis, sehingga dilakukan pemanasan untuk menguraikan kedua senyawa tersebut yang mungkin telah terbentuk. Hasil pemanasan kalsium oksida menunjukkan adanya massa yang hilang sebesar 0,08 gram yang diduga sebagai uap air dan karbondioksida.

Reaksi Transesterifikasi Terkatalisis Kalsium Oksida

Reaksi transesterifikasi dilakukan dengan metode refluks pada temperatur $70^{\circ} \mathrm{C}$. Reaksi antara kalsium oksida dan reaktan terjadi pada permukaan katalis maka dilakukan pengadukan saat reaksi ini berlangsung agar reaksi dapat berjalan dengan sempurna selama 3 jam karena interaksi yang terjadi antar partikel dalam larutan lebih cepat. Temperatur, waktu, rasio alkohol terhadap minyak, jenis dan jumlah katalis serta pengadukan sangat berpengaruh dalam reaksi transesterifikasi, oleh sebab itu hal-hal tesebut diperhatikan [9].

Mekanisme reaksi transesterifikasi terkatalisis kalsium oksida ditunjukkan dalam gambar 1 [10]. Asam laurat merupakan komponen asam lemak yang paling banyak dalam VCO, oleh sebab itu asam laurat diduga mejadi asam lemak yang paling banyak bereaksi untuk membentuk etil ester [10]. Penggunaan kalsium oksida sebagai katalis dalam reaksi ini sangat menurunkan kemungkinan terjadinya reaksi penyabunan karena katalis tidak dapat larut dalam reaktan akan tetapi persentase menurunnya rendemen dapat meningkat karena kemampuan kalsium oksida untuk mengabsorbsi. Kalsium oksida juga mudah untuk dipisahkan dari hasil reaksi yaitu dengan cara disaring meskipun terdapat partikel-partikel kalsium oksida berukuran sangat kecil yang masih terdapat pada hasil reaksi.

Karakteristik Hasil Reaksi Transesterifikasi Virgin Coconut Oil Terkatalisis Kalsium Oksida Sifat Fisiko Kimia

Rendemen yang diperoleh sebesar 39,89\%, hasil ini menunjukkan penurunan jika dibandingkan dengan rendemen transesterifikasi menggunakan katalis homogen yang disebabkan oleh terabsorbsinya reaktan kedalam kalsium oksida. Sementara itu, viskositas dan massa jenis mengalami penurunan yang diduga terjadi karena trigliserida telah pecah menjadi suatu etil ester. Viskositas dan massa jenis menurun jika rantai karbon semakin pendek yang menandakan reaksi transesterifikasi berhasil terjadi karena adanya pembentukan rantai yang mengikat asam lemak menjadi lebih pendek [11] .

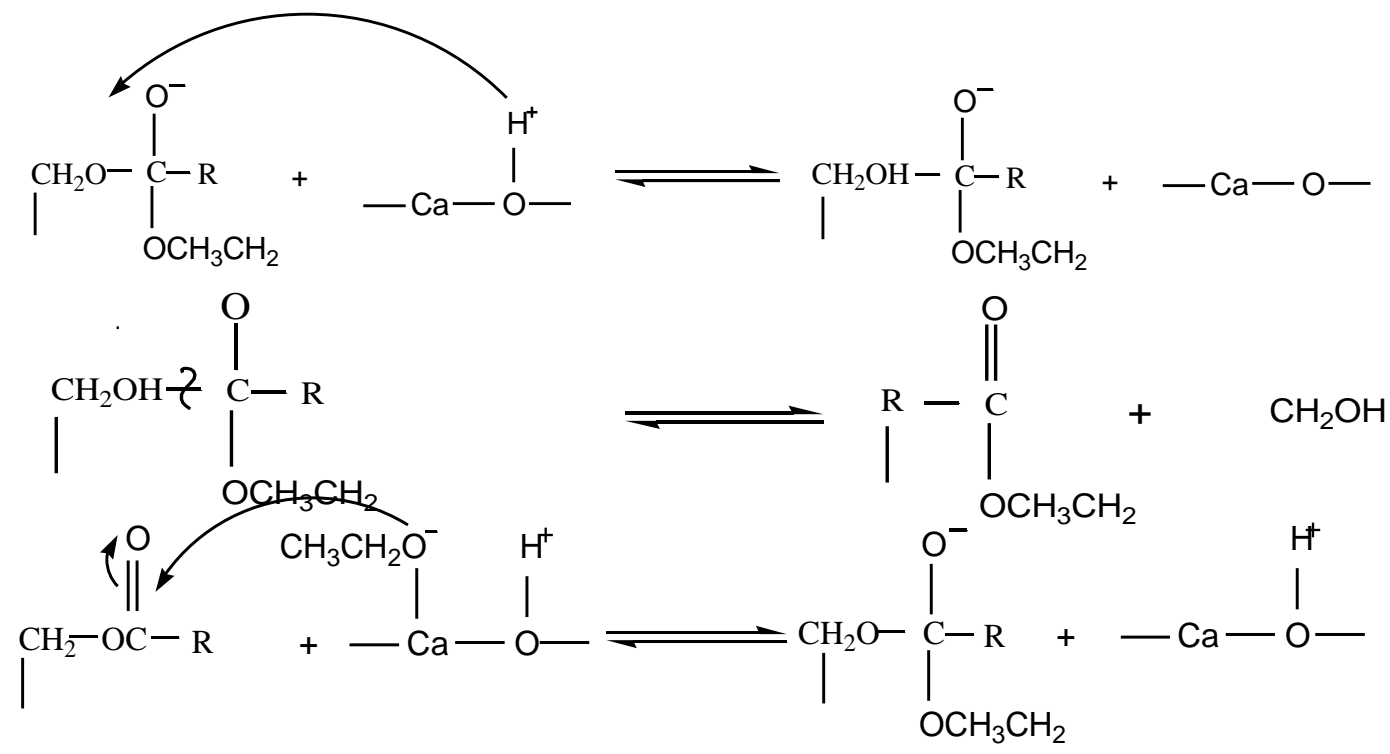

Gambar 1. Mekanisme reaksi transesterifikasi terkatalisis kalsium oksida 
Tabel 2. Sifat Fisiko Kimia Hasil Reaksi Transesterifikasi Terkatalisis Kalsium Oksida

\begin{tabular}{|c|c|c|}
\hline Parameter & $\begin{array}{c}\text { Etil Ester } \\
\text { Minyak } \\
\text { Kelapa } \\
\end{array}$ & Satuan \\
\hline Rendemen & 39,89 & $\%$ \\
\hline $\begin{array}{l}\text { Massa jenis } \\
\text { pada } 40^{\circ} \mathrm{C}\end{array}$ & 0,88 & $\mathrm{~g} / \mathrm{mL}$ \\
\hline $\begin{array}{l}\text { Viskositas } \\
\text { kinematik } \\
\text { pada } 40^{\circ} \mathrm{C}\end{array}$ & 2,73 & $\mathrm{~mm}^{2} / \mathrm{s}(\mathrm{cSt})$ \\
\hline $\begin{array}{l}\text { Bilangan } \\
\text { asam }\end{array}$ & 0,59 & $\begin{array}{c}\mathrm{mg}-\mathrm{KOH} / \mathrm{g} \\
\text { maks }\end{array}$ \\
\hline $\begin{array}{l}\text { Bilangan } \\
\text { ester }\end{array}$ & 148,43 & $\mathrm{mg}-\mathrm{KOH} / \mathrm{g}$ \\
\hline $\begin{array}{l}\text { Bilangan } \\
\text { peroksida }\end{array}$ & 4,27 & mek $\mathrm{O}_{2} / \mathrm{kg}$ \\
\hline
\end{tabular}

Parameter bilangan asam, bilangan peroksida dan bilangan ester mengalami kenaikan diduga karena adanya pemanasan pada saat refluks yang dilakukan pada temperatur $70^{\circ} \mathrm{C}$ selama 3 jam (tabel 2).

\section{Analisis Kromatografi Gas-Spektrometri Massa}

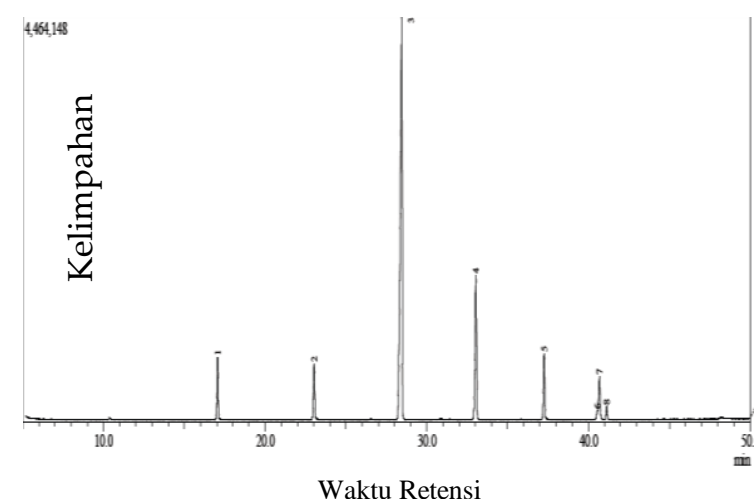

Gambar 2. Kromatogram hasil Reaksi

Transesterifikasi VCO terkatalisis kalsium oksida.

Dari kromatogram yang diperoleh terdapat delapan komponen dalam sampel hasil reaksi transesterifikasi virgin coconut oil terkatalisis kalsium oksida dimana masingmasing memiliki waktu retensi 17,$06 ; 23,03$; 28,$45 ; 33,04 ; 37,27 ; 40,54 ; 40,69$; dan 41,13. Delapan komponen tersebut diduga sebagai etil kaprilat, etil kaprat, etil laurat, etil miristat [12], etil palmitat [13], etil oleat [14] dan etil stearat [14] melalui pencocokan dengan fragmentasi senyawa-senyawa yang tersedia dalam data base dan beberapa literatur. Dalam kromatogram hasil reaksi transesterifikasi terkatalisis kalsium oksida (gambar 2) terdapat tiga puncak yang dengan kelimpahan terbesar yaitu puncak tiga dengan kelimpahan 58,32\% diduga sebagai etil laurat. Puncak empat dengan kelimpahan $16,82 \%$ dan puncak lima sebesar $6,92 \%$ diduga sebagai etil miristat dan etil palmitat.

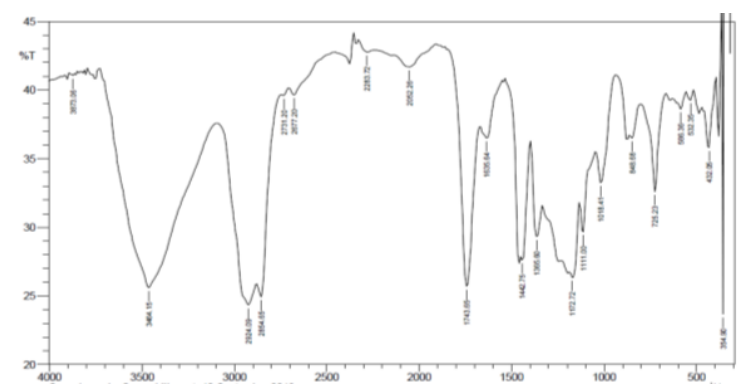

Gambar 3. Spektrum inframerah hasil reaksi transesterifikasi VCO terkatalisis kalsium oksida.

\section{Spektrofotometri Inframrah}

Spektrofotometri inframerah digunakan untuk melihat gugus fungsi yang ada (gambar 3). Etil ester memiliki gugus-gugus fungsi yang dapat diketahui dengan spektrofotometri inframerah seperti $\mathrm{C}=\mathrm{O}, \mathrm{C}-\mathrm{O}, \mathrm{C}-\mathrm{H}$ dan $\mathrm{C}-\mathrm{C}$ (tabel 3).

Tabel 3. Interpretasi spektrum inframerah

\begin{tabular}{|c|c|c|c|}
\hline Ikatan & Intensitas & $\begin{array}{c}\text { Bentuk } \\
\text { pita }\end{array}$ & $\begin{array}{c}\text { Panjang } \\
\text { Gelombang } \\
\mathrm{cm}^{-1}\end{array}$ \\
\hline $\mathrm{O}-\mathrm{H}$ & Kuat & Tajam & 3463,15 \\
\hline C-H $s p^{3}$ & Kuat & Tajam & $\begin{array}{c}2924,09 \text { dan } \\
2854,65\end{array}$ \\
\hline $\begin{array}{l}\mathrm{C}=\mathrm{O} \\
{[13]}\end{array}$ & Kuat & Tajam & 1743,65 \\
\hline $\begin{array}{l}\text { Regangan } \\
\mathrm{C}=\mathrm{C}\end{array}$ & Kuat & Lemah & 1635,64 \\
\hline $\mathrm{C}-\mathrm{O}$ & Kuat & $\begin{array}{c}\text { Sedikit } \\
\text { lebar }\end{array}$ & 1172,72 \\
\hline
\end{tabular}

Ikatan O-H muncul pada panjang gelombang sekitar $3462,22 \mathrm{~cm}^{-1}$ dan ikatan $\mathrm{C}=\mathrm{C}$ muncul pada panjang gelombang sekitar $1651,07 \mathrm{~cm}^{-1}$ [15]. Selain itu, panjang gelombang $2840 \mathrm{~cm}^{-1}-3000 \mathrm{~cm}^{-1}$ menunjukkan adanya ikatan C-H sp $\quad 1735 \quad \mathrm{~cm}^{-1} \quad-1750 \quad \mathrm{~cm}^{-1}$ menunjukkan adanya serapan karbonil untuk 
ester dan panjang gelombang $1250 \mathrm{~cm}^{-1}, 1205$ $\mathrm{cm}^{-1}, 1175 \mathrm{~cm}^{-1}$ menunjukkaan serapan C-O untuk ester yang mengikat asam lemak [16]. Serapan $\mathrm{OH}$ yang dihasilkan diduga karena masih adanya $\mathrm{Ca}(\mathrm{OH})_{2}$ dalam hasil reaksi. $\mathrm{Ca}(\mathrm{OH})_{2}$ tersebut diduga terbentuk karena adanya kandungan air dalam sampel meskipun sangat kecil.

\section{Kesimpulan}

Kalsium oksida dapat mengkatalisis reaksi transesterifikasi VCO dan etanol dan memberikan karakteristik fisiko-kimia serta analisis KGSM dan IR yang diduga merupakan etil ester dengan tiga puncak yang memiliki kelimpahan terbanyak berupa etil laurat $58,32 \%$, etil miristat $16,82 \%$ dan etil palmitat $6,92 \%$.

\section{Daftar Pustaka}

1. Gugule, S.; Fatimah,F., Karakterisasi Virgin Coconut Oil (VCO) Rempah.Chemistry Progres, 2010, 3, (2).

2. Gugule, S.; Fatimah, F.; Maanari, P.C.; Tallei, E.T., Data on the Use of Virgin Coconut Oil and Bioethanol Produced From Sugar Palm Sap as Raw Materials for Biodisel Synthesis. 2020, 29, 105-199.

3. Semwal, S; Arora, A.K; Badoni, R.P; Tuli, D.K., Biodiesel Production Using Heterogeneous Catalyst. Bioresource Technology. 2011, 102, (3), 2151-2161.

4. AOAC., Official Methods of Analysis, Assoc.Offic.Anal.Chem. Washington DC, 1990.

5. Empikul, N.; Krasae, P.; Nualpaeng, W.; Yoosuk,B.; Faungnawakij, K., Biodiesel Production Over Ca-Based Solid Catalysts Derived Fromindustrial Wasters. Fuel. 2012. 92,(1), 239-244.

6. Gugule, S; Maanari,P.C., Identification Of Major Components Of Ethyl Ester From Coconut Oil Trough Gas ChromatographyMass Spectrometer. Proceedings of The Global Conference On Education And Science. 2018. 1, 116-119.

7. Murti, W.G.; Rahmawati,N.; Heriyanti, I.S.; Hastuti, D.Z., Optimasi Proses Produksi Biodisel Dari Minyak Kelapa Sawit Dan Jarak Pagar Dengan Menggunakan Katalis Heterogen Kalsium Oksida. Jurnal Energi dan Lingkungan. 2015, 11, (2), 91-100.
8. Granados, M. L.; Poves, M. Z.; Alonso, D. M.; Mariscal, R.; Galisteo, F. C.; MorenoTost, R.; Santamaria,J.; Fierro, J. L. G., Biodiesel From Sunflower Oil by Using Activated Calcium Oxide. Applied Catalysis B: Environmental, 2007, 73, 3-4, 317-326.

9. Gashaw,A.; Getachew,T.; Teshita,A., A Review on Biodisel Production As Alternative. Fuel, 2015, 80-85.

10. Liu, X.; He,H.; Wang, Y.; Zhu, S.; Piao,X., Transesterification of soybean oil to biodisel using $\mathrm{CaO}$ as a solid base catalyst. Fuel, 2008, 87, 216-221.

11. Ratno.; Mawarani, J. L.; Zulkifli., Pengaruh Ampas Tebu sebagai Adsorbent pada Proses Pratreatment Minyak Jelantah terhadap Karakteristik Biodisel. Jurnal Teknik Fisika. 2013, 2, (2), 2337-3539.

12. Alfy, El.T; Tantawy, M; Motal, A.A; Gamal, Z. F., Pharmacological Biological Study and GC/MS Analysis of the Essential Oil of The Aeril and the Alcohol Soluble Fraction of the N.Hexane Extract of the Flowers of Reichardia TingitanaL. Canadian Journal of Pure and Applied Science. 2015. 9, 3167-3175.

13. Aisyah.; Riskayanti.; Novianti, I.; Sjamsiah.; Ilyas, A.; Chadijah, S., Produksi Etil Ester dari Minyak Dedak Padi (Oryza sativa) Menggunakan Reaktor Ultrasonik. Al-Kimia. 2018. 6, (1), 34-35.

14. Jusman.; Setiaji, B.; Triyono.; Syoufian, A., Fractination Of Medim Chain Fatty Acid Ethyl Esters From Virgin Coconut Oil Via Transesterification and Distillation Under Reduced Pressure. International Journal of Basics \& Applied Science 2013. 13, (01), 60-64.

15. Al,Y.; Aisyah.; Suriani., Sintesis Etil Ester Dari Minyak Biji Kemiri (Aleurites Mollucana). Al-Kimia. 2015. 3, (2), 100-109.

16. Silverstein, R.M.; Webster, F.X.; Kiemle, D.J., Spectrrometric Identification of Organic Compounds. $7^{\text {th }}$ edition. John Wiley\&Sons. New York, 2005.

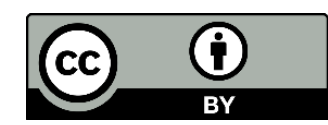

(C) 2020 by the authors. Licensee Fullerene Journal Of Chem. This article is an open access article distributed under the terms and conditions of the Creative Commons Attribution (CC BY) license

(http://creativecommons.org/licenses/by/4.0/). 